\title{
INTEGRAÇÃO DE DADOS DE RADAR, AEROGAMAESPECTROMÉTRICOS E GEOLÓGICOS NOS DOMÍNIOS DO COMPLEXO GRANÍTICO ESTRELA, PROVÍNCIA MINERAL DE CARAJÁS
}

\author{
EDSON RICARDO SOARES PEREIRA DA CUNHA ${ }^{1,2}$, ATHOS RIBEIRO DOS SANTOS ${ }^{2}$, \\ WALDIR RENATO PARADELLA², CARLOS EDUARDO DE MESQUITA BARROS ${ }^{3}$, \\ PAULO VENEZIANI ${ }^{2}$ (IN MEMORIAM) \& ARMÍNIO GOUVEIA DO VALE ${ }^{4}$
}

\begin{abstract}
Resumo Distintos produtos integrados de radar foram avaliados na caracterização geológica do Complexo Granítico Estrela, situado na borda ocidental da Província Mineral de Carajás. O Complexo Granítico Estrela é considerado um dos maiores representantes do evento de granitização sintectônica que ocorreu no Arqueano do Craton Amazônico. A integração digital de dados de radar de abertura sintética (SAREX) com dados aerogeofísicos gamaespectrométricos e geológicos permitiu a visualização da distribuição espacial dos domínios geológicos (Complexo e suas encaixantes), favoreceu a reavaliação de dados prévios e confirmou, de modo geral, a distribuição espacial de fácies magmáticas internas do Complexo Granítico Estrela. Por ser um sensor de excelência na caracterização de relevo topográfico, controlado pela geologia estrutural e por padrões erosivos das litologias, a contribuição do radar no produto integrado esteve ligada às variações de atributos texturais, enquanto que o componente de matiz foi controlado pelas respostas gamaespectrométricas das rochas. As áreas de maiores respostas gamaespectrométricas corresponderam aos domínios de monzogranitos ricos em biotita, distribuídos em áreas de altitudes algo mais elevadas, e que apresentam maiores concentrações de $\mathrm{K}_{2} \mathrm{O}, \mathrm{Th}, \mathrm{U}, \mathrm{Rb}$ e de elementos terras raras. A utilização deste tipo de abordagem em mapeamento geológico e exploração mineral é relevante considerando-se o potencial econômico da Província Mineral de Carajás e a contribuição na redução de custos dos trabalhos de campo.
\end{abstract}

Palavras-chave: radar imageador, SAREX, aerogamaespectrometria, Complexo Granítico Estrela, Carajás.

\begin{abstract}
INTEGRATION OF RADAR, AEROGAMMASPECTROMETRIC AND GEOLOGICAL DATA IN THE DOMAINS OF THE ESTRELA GRANITE COMPLEX, CARAJAS MINERAL PROVINCE.. SAR (Synthetic Aperture Radar) products were evaluated for geological characterization of the Estrela granite complex, Pará State, Brazilian Amazon. The Complex is located on the southeastern border of the Amazonian Craton, and is considered a representative of the Archean syntectonic granitization event within the Carajás Mineral Province. The integration of airborne C-HH SAR (SAREX) with airborne gamma ray (Total Count) and geology (map of internal facies) has provided a powerful tool for terrain visualization, for re-evaluation of previous data and also confirmed information regarding the spatial distribution of internal petrographic facies. In the integrated product, SAR imagery has contributed with valuable textural information related to geological structures and erosion expression of lithologies, while airborne gamma-ray (Total Count) was useful in the discrimination of rock units, closely related to hue variation, allowing the discrimination of distinct domains (granite complex and host rocks, internal magmatic facies). The areas with stronger gammaespectrometric responses are spatially related to biotite monzogranites, which have higher concentrations of potassium, uranium, thorium, rubidium and rare-earth elements. Diabase dikes and brittle structures were also easily identified on the integrated product. Furthermore, structural patterns were revealed for the whole granite complex and host rocks, showing the importance of synoptic view for mapping purposes. The application of this approach in geological and exploration programs in similar areas of the Amazon is important due to the general absence of geological information with spatial attributes and the reduction of expenses for field campaigns.
\end{abstract}

Keywords: imaging radar, SAREX, aerogammaspectrometry, Estrela granite complex, Carajás.

INTRODUÇÃO A integração digital de sensores remotos com dados de outra natureza (Geofísica, Geologia, Geoquímica, etc) tem sido freqüentemente utilizada em aplicações geológicas através do uso de transformação IHS (Intensity-Hue-Saturation), tal como proposto por Harris et al. (1994). No Brasil, muitos autores têm utilizado este tipo de abordagem, particularmente na integração de dados de radar, ópticos e aerogeofísicos em aplicações geológicas no trópico úmido (Rolim 1993, Bicho 1994, Dias \& Paradella 1997, Santos 1999, Pedroso et al. 2001, Siqueira 2003, entre outros). Na Província Mineral de Carajás, trabalhos sucessivos explorando integrações digitais têm permitido aprimorar a cartografia geológica de áreas de difícil acesso, a exemplo dos Granitos Central (Paradella et al. 1997, 1998, Santos et al. 1997) e Cigano (Teruyia, 2002), bem como fornecer subsídios na proposição de modelos de evolução tectônica (Veneziani et al. 2004).
Os primeiros trabalhos de cartografia geológica de detalhe sobre a parte centro-oriental do Complexo Granítico Estrela foram realizados em 1988, quando da realização da disciplina Estágio de Campo III pelos alunos e professores do Curso de Geologia da UFPA (Costa et al. 1990). O estudo deste setor do maciço teve prosseguimento com a dissertação de mestrado de Barros (1991). Paralelamente, desenvolveu-se na região de Carajás o Programa de Levantamentos Geológicos Básicos (Companhia de Pesquisa de Recursos Minerais / SUREG Belém), quando se produziram numerosos dados, mapas aerogamaespectrométricos e mapas lito-estruturais (Araújo \& Maia 1991).

Estudos mais detalhados sobre a petrologia, estrutura e mecanismos de colocação do Complexo Granítico Estrela resultaram da tese de doutorado de Barros (1997) e dos trabalhos subseqüentes (Barros \& Barbey 1998, Barros et al. 2001, Barros et al. 2004). Na tese de Barros (1997), os trabalhos de campo envol-

\footnotetext{
1 - Centro de Pesquisas e Desenvolvimento Leopoldo Américo Miguez de Mello (CENPES) - Petróleo Brasileiro S.A. (PETROBRAS), RJ, ercunha@petrobras.com.br

2 - Instituto Nacional de Pesquisas Espaciais (INPE) - São José dos Campos, SP, \{athos, waldir\}@ltid.inpe.br

3 - Universidade Federal do Pará, Departamento de Geoquímica e Petrologia, - Grupo de Pesquisa em Petrologia de Granitóides, Belém, PA, cadu@ufpa.br

4 - Companhia de Pesquisa de Recursos Minerais (CPRM) - Superintendência de Belém (SUREG), Belém, PA, agvale@be.cprm.gov.br
} 

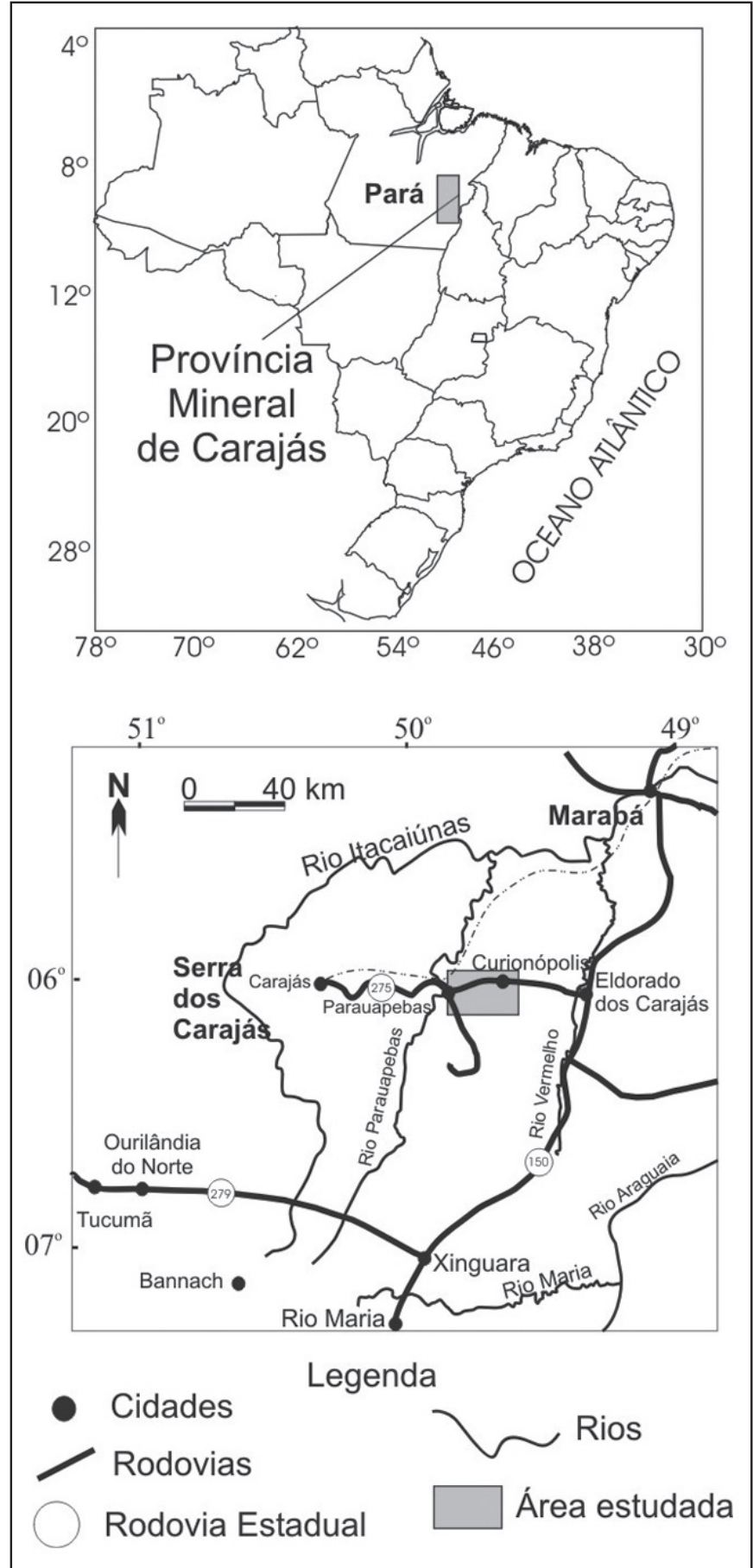

Figura 1. Localização da área de pesquisa (Serra dos Carajás).

veram os métodos clássicos de cartografia e os dados de atitudes de elementos estruturais foram lançados em estereogramas e em mapa, o que permitiu mostrar as trajetórias de foliações. Foi desenvolvido, também, um estudo petrográfico onde as análises modais (1500 pontos) de 64 lâminas delgadas e a estimativa de cerca de 40 outras lâminas delgadas possibilitaram a classificação das rochas ( $c f$. Streckeisen 1976) e a separação de fácies com base na proporção de minerais ferromagnesianos, sendo que aquele mais abundante está escrito mais próximo do nome da rocha. As análises químicas foram feitas nos laboratórios do Centro de Geociências da UFPA e nos Laboratórios do Centre de Recherches Pétrographiques et Géochimiques (Vandoeuvrelès-Nancy, França). As primeiras, obtidas por Fluorescência de Raios-X, Absorção Atômica e Titulometria, determinaram as concentrações de elementos maiores e alguns elementos-traço ( $\mathrm{Rb}, \mathrm{Sr}, \mathrm{Y}, \mathrm{Nb}$ e $\mathrm{Zr}$ ), ao passo que as últimas são completas e obtidas por ICP-MS.

A evolução estrutural e metamórfica da Província Mineral de Carajás, em grande parte de idade arqueana, foi marcada pela intrusão de vários granitos sintectônicos (Barros et al. 2001) e pelo desenvolvimento de zonas de cisalhamento de comprimentos quilométricos (Pinheiro \& Holdsworth 1997, Veneziani et al. 2004). A maior ou menor ênfase em um ou outro estilo estrutural (zonas de cisalhamento vs. granitos sintectônicos) tem estimulado propostas evolutivas distintas, cuja validação pode ser facilitada pela integração de informações de observações de campo com as providas espacialmente pelos recobrimentos dos sensores remotos e aerogeofísicos.

Neste trabalho serão discutidos resultados da integração de dados de diferentes fontes na caracterização geológica do Complexo Granítico Estrela e suas rochas encaixantes. A área estudada (figura 1) com cerca de $1000 \mathrm{~km}^{2}$ localiza-se a leste da Serra dos Carajás, compreendendo parte dos municípios de Parauapebas e Curionópolis e é delimitada pelas coordenadas UTM 622000, 9328000 e 658000, 9302000 (coordenadas geográficas $6^{\circ} 4$ ' $55^{\prime \prime}$ de latitude sul, $49^{\circ} 53$ ' $51^{\prime \prime}$ de longitude oeste, $6^{\circ} 18^{\prime} 46^{\prime \prime}$ de latitude sul e $49^{\circ} 34^{\prime} 17^{\prime \prime}$ de longitude oeste).

GEOLOGIA REGIONAL A Província Mineral de Carajás (PMC) é constituída a sul pelo terreno granito-greenstone de Rio Maria e a norte pela região da Serra dos Carajás e suas adjacências (DOCEGEO 1988), na qual se situa a área estudada. A unidade mais antiga do setor norte compreende os granulitos máficos, charno-enderbitos e enderbitos do Complexo Pium, os quais formam corpos alongados na direção E-W (DOCEGEO 1988, Araújo \& Maia 1991). Idades U-Pb em zircão mostram idades de cristalização em torno de 3,0 Ga e de granulitizacão de 2,87 Ga (Pidgeon et al. 2000). Metagranitóides ocorrem de modo localizado (Machado et al.1991), cujas datações U-Pb em zircão fornecem idades em torno de $2,85 \mathrm{Ga}$. $\mathrm{Na}$ região de $\mathrm{Ca}$ naã dos Carajás outras ocorrências de granitóides contemporâneos têm sido identificadas (Gomes \& Dall'Agnol 2003). Estas rochas foram recobertas por extensas seqüências de metabasaltos e metagabros, formações ferríferas bandadas e quartzitos, além de subordinados metapelitos do Supergrupo Itacaiúnas (DOCEGEO 1988).

As rochas do Supergrupo Itacaiúnas são cortadas por vários granitos sintectônicos arqueanos, representados pelos granitos Estrela (Barros et al. 2001), Plaquê (Macambira et al. 1996), Planalto (Huhn et al. 1999), Serra do Rabo (Sardinha et al. 2006) e pelos granitos da região do Igarapé Gelado (Barbosa \& Barros 2005). Diversas datações U-Pb e Pb-Pb em zircão têm apontado idades entre 2,74 e 2,76 Ga para estes granitos. Os metabasaltos do Supergrupo Itacaiúnas sofreram efeitos de metamorfismo de contato e de deformação dúctil em resposta à expansão lateral durante a colocação destes granitos (Barros \& Barbey 1998, Barros et al. 2001, Sardinha et al. 2006). Pequenos corpos de anortositos e de rochas ultramáficas afloram nas proximidades da Serra Pelada e são atribuídos ao Complexo Luanga (DOCEGEO 1988), cuja idade de cristalização seria de 2,763 Ga (Machado et al. 1991). Diques e soleiras de gabros hidrotermalizados ocorrem no platô da Serra dos Carajás, a oeste do Granito Central dos Carajás e cortam arenitos da Formação Águas Claras (Soares et al. 1994).

Ao longo da evolução da Província Mineral de Carajás, houve diferentes momentos de desenvolvimento de zonas de cisalhamento dúctil, dúctil-rúptil e rúptil-dúctil, caracterizadas por comprimentos quilométricos, espessuras decamétricas e direção WNW-ESE. Algumas destas estruturas são representadas pela Falha Carajás e pelo Lineamento Cinzento (Pinheiro \& Holdsworth 1997). Os granitos paleoproterozóicos anorogênicos (eg. Cigano 
e Central dos Carajás) têm formas irregulares, discordantes das estruturas regionais (DOCEGEO 1988). Diversas datações apontam idades de 1,888 Ga para estas rochas (Machado et al. 1991). Rochas vulcânicas máficas a félsicas paleoproterozóicas afloram de modo subordinado na região (Rivalenti et al. 1998). Localmente afloram arenitos e conglomerados atribuídos à Formação Gorotire, os quais teriam sido depositados em depressões associadas à Falha Carajás e suas ramificações (Lima \& Pinheiro 2001).

O COMPLEXO GRANÍTICO ESTRELA Estruturas das rochas encaixantes.O Complexo Granítico Estrela corta metabasaltos aos quais se intercalam camadas de formações ferríferas bandadas e quartzitos, além de domínios subordinados de metapelitos e raras rochas metaultramáficas (Docegeo 1988, Barros 1997). Dada a sua maior resposta aos efeitos intempéricos, os metabasaltos formam uma área de relevo aplainado de menores altitudes, que contrasta com as colinas do Complexo Granítico Estrela e com as serras estreitas e alongadas sustentadas por formações ferríferas e quartzitos. É importante notar que estas serras de formações ferríferas tendem a se amoldar

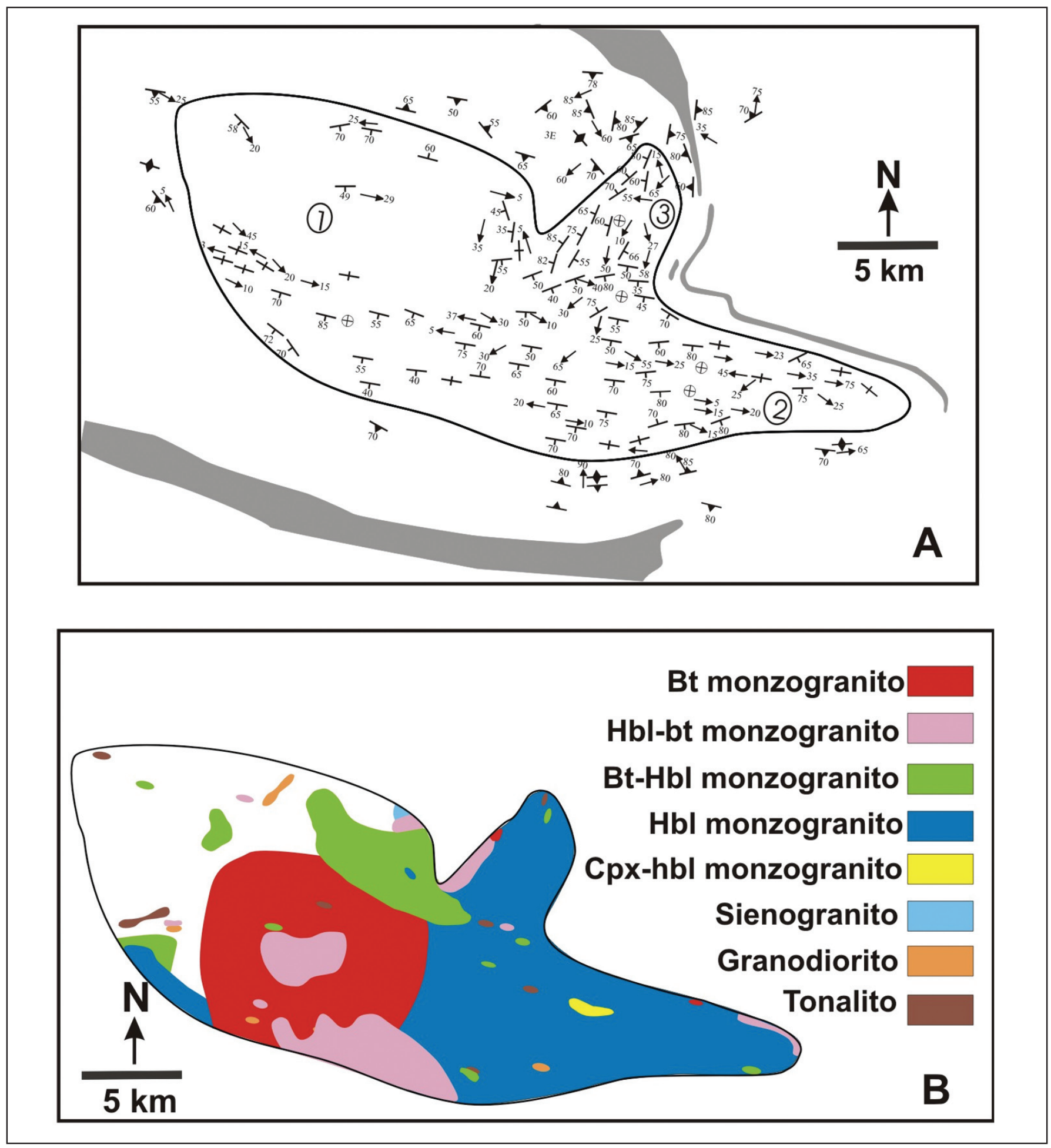

Figura 2. Complexo Granítico Estrela: (A) estruturas; (B) fácies petrográficas. Fonte: Barros 1997. 
Tabela 1. Principais características da imagem SAREX.

\begin{tabular}{|c|c|c|c|c|c|c|}
\hline Sensor/ & $\begin{array}{c}\text { Ângulos de } \\
\text { Incidência } \\
\text { Modo }\end{array}$ & $\begin{array}{c}\text { Resolução } \\
\text { espacial })\end{array}$ & $\begin{array}{c}\text { Espaçamento } \\
\text { de Pixel } \\
(\mathrm{m})(\mathbf{r} \times \text { az) }\end{array}$ & $\begin{array}{c}\mathbf{N}^{\circ} \text { looks } \\
(\mathrm{m})\end{array}$ & $\begin{array}{c}\text { Formato da } \\
\text { Imagem }\end{array}$ & $\begin{array}{c}\text { Azimute de } \\
\text { Iluminação }\end{array}$ \\
\hline $\begin{array}{c}\text { SAR CV 580 } \\
\text { C-HH }\end{array}$ & $\mathbf{4 5}^{\circ}-\mathbf{8 5}^{\circ}$ & $18,7 \times 9,8$ & $15 \times 6,9$ & 7 & 8 -bits & $282^{\circ}$ \\
\hline
\end{tabular}

aos contatos do corpo granítico. A nordeste do granito se forma uma dobra de grande escala resultante da interferência de esforços compressivos regionais com os esforços de expansão lateral provocado pela colocação do corpo granítico (Barros et al. 2001). Os efeitos deformacionais e térmicos provocados pelo granito criaram ao seu redor uma auréola, de aproximadamente $1,5 \mathrm{~km}$ de largura, na qual há anfibolitos foliados com textura nematoblástica, bem como fraturas hidráulicas e veios de anfibólio (Barros et al. 2002).

Geologia Estrutural O Complexo Granítico Estrela (figura 2A) tem forma alongada na direção WNW-ESE, concordante com as estruturas regionais, as quais são marcadas pelo alinhamento de serras de formações ferríferas e de quartzitos e pela xistosidade de rochas metavulcanossedimentares. $\mathrm{Na}$ parte norte do complexo há uma pequena protuberância, de direção aproximadamente NE-SW, cuja forma lembra a de uma barbatana. Internamente o Complexo Granítico Estrela tem um bandamento primário $\left(\mathrm{S}_{0}\right)$, marcado pela alternância de níveis ricos em minerais máficos e níveis mais enriquecidos em quartzo e feldspatos. Este bandamento primário tende a acompanhar os limites do complexo e por isto assume um arranjo concêntrico. Nas partes centrais dos plútons, o bandamento $\mathrm{S}_{0}$ pode ter mergulho subhorizontal ou de baixo ângulo, ao passo que nas porções periféricas esta superfície tem mergulhos subverticais. Uma foliação $\left(\mathrm{S}_{1}\right)$, penetrativa na escala do corpo, é marcada pela orientação preferencial de minerais máficos, de feldspatos e pelo achatamento dos cristais de quartzo. Esta superfície tem direção predominante WNW-ESE e ângulos de mergulho que variam de vertical a $70^{\circ} \mathrm{S}$, podendo em muitos locais superpor-se ao bandamento primário. Na parte central do maciço, a foliação $\mathrm{S}_{1}$ mostra leve mudança de trajetória, a qual tende a acompanhar os limites entre hornblenda monzogranitos e biotita monzogranitos. Na parte norte do complexo, a foliação $S_{1}$ tem trajetórias concordantes com a forma deste pequeno plúton orientado na direção NE-SW. Nas proximidades da zona de confluência de trajetórias de foliação, notam-se padrões complexos de dobras decimétricas a métricas que resultam da interferência dos esforços de colocação dos diferentes plútons com os esforços regionais (Barros \& Barbey 1998, Barros et al. 2001).

Zonas miloníticas $\left(\mathrm{S}_{1 \mathrm{~m}}\right)$ de espessura decimétrica a métrica e, em geral, concordantes à foliação $\mathrm{S}_{1}$, limitam-se ao interior do maciço, não afetando as encaixantes. $\mathrm{O}$ conjunto de estruturas registra uma transição dos estágios magmáticos não completamente consolidados para o completamente consolidado de altas a baixas temperaturas (Barros et al. 2001) e atesta a natureza sintectônica deste maciço. As zonas miloníticas são interpretadas como locais de ajustes mecânicos (cf. Gapais 1989), tardios na história de colocação do maciço granítico. Barros et al. (2001) sugerem que a atuação de esforços regionais, representados pelo encurtamento sub-horizontal de direção NS teria sido responsável pela criação de uma fratura de tensão, a qual teria sido aproveitada para a colocação do plúton menor (barbatana), situado na parte norte do maciço (figura 2B).

Distribuição de Fácies A cartografia do Complexo Granítico Estrela (Barros et al. 2001) permitiu discriminar dois tipos petrográficos principais: na parte oriental e a norte do maciço predominam hornblenda monzogranitos e, em uma área subcircular na parte centro-ocidental prevalecem os biotita monzogranitos (figura 2B). Domínios menores com formas algo irregulares, mas também alongadas aproximadamente na direção E-W representam biotita-hornblenda monzogranitos na parte norte e hornblenda-biotita monzogranitos no extremo sul do corpo. Porções menores de uma fácies petrográfica qualquer se intercalam por vezes a rochas de outra fácies, tais como sienogranitos, granodioritos e tonalitos. Muitas vezes, esta heterogeneidade petrográfica se nota na escala de afloramento, com diferentes monzogranitos, cortados por veios aplíticos e pegmatóides quartzofeldspáticos, o que resulta em arranjos algo complexos.

As partes em branco no mapa de fácies são áreas não amostradas, devido à presença de cobertura vegetal ou à ausência de acessos, quando da cartografia de fácies (Barros 1997, Barros et al. 2001). Entretanto, é provável que nestes locais predominem biotita-hornblenda monzogranitos, haja vista a presença de áreas descontínuas desta fácies nas partes ocidentais do maciço.

CONJUNTO DE DADOS A imagem digital de radar utilizada como referência na geração dos produtos integrados foi obtida por meio do levantamento aéreo na área pelo SAREX (South American Radar Experiment). O SAREX foi um amplo programa de imageamento de radar em banda $\mathrm{C}$ realizado na Amazônia brasileira durante o mês de abril de 1992, com o objetivo de simulação de recobrimentos orbitais previstos nos satélites RADARSAT-1 e ERS-1. Neste experimento foi utilizada a aeronave canadense CONVAIR 580 com o sensor de radar de abertura sintética SAR-CV 580, com sobrevôos na PMC a uma altitude média de $6 \mathrm{~km}$, gerando imagens na banda $\mathrm{C}(5,6 \mathrm{~cm})$, com polarizações paralelas (HH, VV) e cruzadas (HV, VH), sob diferentes geometrias de imageamento e resolução espacial 
(modos Narrow, Nadir e Wide). A faixa BRA 4.1, modo amplo (Wide), que engloba a área de pesquisa, está disposta segundo a orientação N13E e direção de visada para oeste, isto é, segundo à trajetória prevista das órbitas descendentes dos imageamentos do RADARSAT-1 e ERS-1. Somente a imagem com a polarização paralela horizontal $(\mathrm{C}-\mathrm{HH})$ foi utilizada nesta investigação, embora também estivesse disponível a imagem de polarização paralela vertical (tabela 1).

Os dados aerogamaespectrométricos foram fornecidos pela CPRM e têm como fonte os levantamentos realizados no período de 1975-1976 pelo Projeto Geofísico Brasil-Canadá (PGBC). $\mathrm{O}$ espaçamento das linhas de vôos sobre a região foi de $2 \mathrm{~km}$ e o intervalo das medições de um segundo, o que correspondeu a aproximadamente $62 \mathrm{~m}$ no terreno. Os dados originais foram fornecidos nos canais de contagem total, potássio, tório e urânio. As unidades gama foram respectivamente ppm (eU, eTh), \% (K) e cps ( Contagem Total). Entretanto para a área-teste, os dados de K não foram utilizados, pois uma análise prévia detectou que o canal estava corrompido, com valores radiométricos originais não condizentes com a geologia e com as respostas esperadas deste canal em relação aos restantes. Finalmente, informações planialtimétricas para a correção geométrica da imagem SAR e navegação em campo foram extraídas da carta topográfica Rio Verde (IBGE 1981), na escala 1: 100.000, projeção UTM com meridiano central $51^{\circ} \mathrm{W}$ e datum de referência SAD 69.

\section{PROCESSAMENTO E INTEGRAÇÃO DIGITAL}

A

imagem digital SAR foi processada no LTID (Laboratório de Tratamento de Imagens Digitais), da Divisão de Sensoriamento Remoto do INPE, em São José dos Campos (SP), com funções de processamento disponíveis no software Geomatica (PCI Geomatics, 2001), abrangendo correções radiométricas (padrão de antena, atenuação de ruído speckle via filtragem Enhanced Frost) e geométrica (transformação polinomial com uso de pontos de controle da carta topográfica). Os dados aerogamaespectrométricos (canais de $\mathrm{CT}, \mathrm{eU}, \mathrm{eTh}$ ) foram processados no Laboratório de Geofísica Aplicada do Instituto de Geociências da Universidade de Brasília, com uso de funções do software Geosoft Oasis Montaj (Geosoft 2000). O processamento consistiu de uma avaliação preliminar dos dados originais (padrão de linhas, testes de consistências, nivelamento), seguida por uma interpolação em malha regular com células de $500 \mathrm{~m}$ x $500 \mathrm{~m}$, no formato GRD, usando interpolador bidirecional. O micronivelamento foi aplicado segundo metodologia proposta por Minty (1997). Finalmente, os dados geofísicos foram reescalados linearmente de 32 para 8 bits e reamostrados para grids de $30 \mathrm{~m}$ (interpolador cúbico). Este valor de $30 \mathrm{~m}$ para o espaçamento de pixel comum para os conjuntos de imagens (SAR, aerogeofísica, temas litológicos) foi decidido em função da acurácia em erro planimétrico da correção geométrica do radar $(30,45 \mathrm{~m}$ em Y e $14 \mathrm{~m}$ em X).

A imagem SAREX foi realçada por ampliação linear (ALC) e não linear (Drieman) de contraste. A integração digital envolveu a combinação da imagem SAR com canais gamaespectrométricos (Produtos SAR/Gama) e SAR com imagem do mapa da distribuição espacial de fácies petrográficas (SAR/Geologia). A integração foi conduzida segundo a regra de que deveria combinar dados complementares entre si, de modo que o produto resultante fornecesse mais informação que a dos componentes isoladamente. A investigação focou no uso de representação de cores através de transformação IHS como técnica efetiva para integrar dados distintos na forma de imagens, produzindo composições multi-fontes georreferenciadas, próprias para interpretações geológicas qualitativas e quantitativas. No caso específico do trabalho foi utilizado o modelo hexacone, no qual o matiz (o comprimento de onda dominante da percepção de cor) e' re- presentado pela posição angular ao redor do topo do hexacone, a saturação (ou grau de pureza da cor) é dada pela distância do eixo vertical central do hexacone, e a intensidade (brilho) é representada pela distância sobre o topo (apex) do hexacone (Mather 1999). Como a percepção de cores decresce com a intensidade (a influência do matiz e da saturação são insignificantes sob valores baixos de intensidade), a transformação IHS baseada em modelos de hexacone tem apresentado um melhor desempenho na integração de sensores remotos com outros diferentes tipos de dados (Harris et al. 1994, 1999). Neste tipo de integração dois conjuntos de dados são combinados: acromáticos e cromáticos. O primeiro relaciona-se com a intensidade, e a imagem de radar tem sido considerada ideal como "input" do canal de intensidade na integração IHS, pois representa informação de elevada freqüência espacial, controlada pela expressão do relevo topográfico, através do realce da macro e micro-topografia. Assim, a imagem SAR realçada foi usada como intensidade. Transformações do tipo pseudo-cor foram aplicadas nas imagens gamaespectrométricas individualmente (CT, U, Th), bem como na imagem de tema geológico (distribuição espacial de fáceis magmáticas), e usadas para modular o componente de matiz na transformação IHS/RBG. Máscaras sintéticas (imagens com valor digital constante) foram usadas como canal de saturação. A imagem SAR realçada e os produtos SAR/Gama e $\mathrm{SAR} / \mathrm{Geologia}$ foram interpretados visualmente.

A metodologia de interpretação geológica dos produtos integrados baseou-se em critérios morfoestruturais estabelecidos para imagens de sensoriamento remoto de baixa resolução espacial (Veneziani \& Anjos 1982), adaptados às peculiaridades das integrações digitais utilizadas neste trabalho, que envolvem dados SAR e gamaespectrométricos. Neste caso, a textura da imagem representa, principalmente, a geometria superficial (morfologia do terreno) fornecida pelos dados de radar; os matizes representam informações sobre variações composicionais das rochas aflorantes, mapeadas pelos dados radiométricos. São, portanto, produtos integrados, onde os dois conjuntos de dados têm papéis distintos e complementares nos procedimentos de fotointerpretação geológica. O ótimo realce morfológico (macro e micro-topografias), característico da visão oblíqua dos sensores SAR, dá fundamento à identificação dos elementos naturais de paisagem, onde são aplicados critérios morfoestruturais que permitem a sua ordenação, repartição e classificação, associando-lhes um significado geológico. Os dados aerogamaespectrométricos, por outro lado, transformados em variações de matiz, de acordo com a intensidade do sinal captado pelo sensor (do azul ao vermelho, em escala crescente de intensidade), trazem importantes informações sobre variações composicionais dos conjuntos litológicos superficiais (indicando a maior ou menor participação dos elementos analisados na composição dos grupos litológicos).

RESULTADOS E DISCUSSÕES Vários produtos foram gerados durante a pesquisa, mas devido às restrições de ilustrações, as discussões a seguir terão como referência somente os produtos apresentados na figura 3. Por ser uma imagem de um espectro radiométrico mais amplo, que inclui a contribuição das radiações individuais de $\mathrm{K}$, $\mathrm{U}$ e Th, a imagem de CT (figura $3 \mathrm{~A}$ ), por apresentar valores de intensidade maior que os outros canais, é estatisticamente mais confiável para a discriminação de variações litológicas (Vasconcellos et al. 1994). A disposição das análises químicas efetuadas por Barros (1997) e identificadas na figura $3 \mathrm{~A}$ não mostra uma correspondência direta entre os teores de $\mathrm{U}$, Th e $\mathrm{K}_{2} \mathrm{O}$ e os matizes da imagem gama CT. Isto se deve a diversos fatores: a baixa resolução dos dados gama CT (2Km entre linhas de vôo), o largo espectro de sensibilidade desse canal (a contribuição não se restringe apenas às radiações 
$\mathrm{K}, \mathrm{U}$ e Th) e pelo caráter pontual e em número reduzido das análises químicas. $\mathrm{O}$ objetivo é mostrar que as maiores respostas gama CT concentram-se nesta região onde, concordantemente, as análises químicas identificaram os maiores valores de $\mathrm{U}, \mathrm{Th}$ e $\mathrm{K}_{2} \mathrm{O}$. Nesta imagem gamaespectrométrica (figura $3 \mathrm{~A}$ ) nota-se o forte contraste radiométrico dos altos valores detectados nos domínios do Complexo Granítico Estrela, em relação aos valores menores dos domínios das rochas supracrustais encaixantes (metabásicas e formações ferríferas bandadas), cujos teores de potássio, urânio e tório e elementos terras raras são menores. Esta imagem também permite observar a forma alongada do complexo e possibilita traçar com mais exatidão os seus limites. As respostas mais elevadas ocorrem na parte centro-ocidental do complexo, onde predominam os biotita monzogranitos. Isto deve refletir os seus teores mais elevados de $\mathrm{K}_{2} \mathrm{O}$, $\mathrm{Rb}$ e de elementos terras raras. Domínios localizados em áreas com respostas radiométricas mais altas parecem representar domínios menores de biotita monzogranitos que podem coexistir com monzogranitos ricos em hornblenda (vide figura. 2A). As camadas verticalizadas de formações ferríferas apresentaram as menores respostas no canal de CT, o que também ocorreu nos canais de Th e U.

A imagem SAREX no modo Wide (tabela 1), representada na figura 3B, retrata as variações de relevo na área de estudo. Apesar do azimute de iluminação de $282^{\circ}$ ser pouco favorável ao realce da estruturação regional WNW-ESE, é possível caracterizar, no centro da área, o corpo do Complexo Granítico Estrela, alongado nesta orientação. O seu relevo é, no geral, mais acidentado (morros arredondados) que no seu entorno, onde predominam os terrenos mais arrasados dos metabasaltos do $\mathrm{Su}-$ pergrupo Itacaiúnas a norte e a sul. As formações ferríferas na porção sudeste da área, alçadas na topografia na forma de serras retilíneas posicionadas perpendicularmente à iluminação SAR, constituem as mais proeminentes feições de imagem.

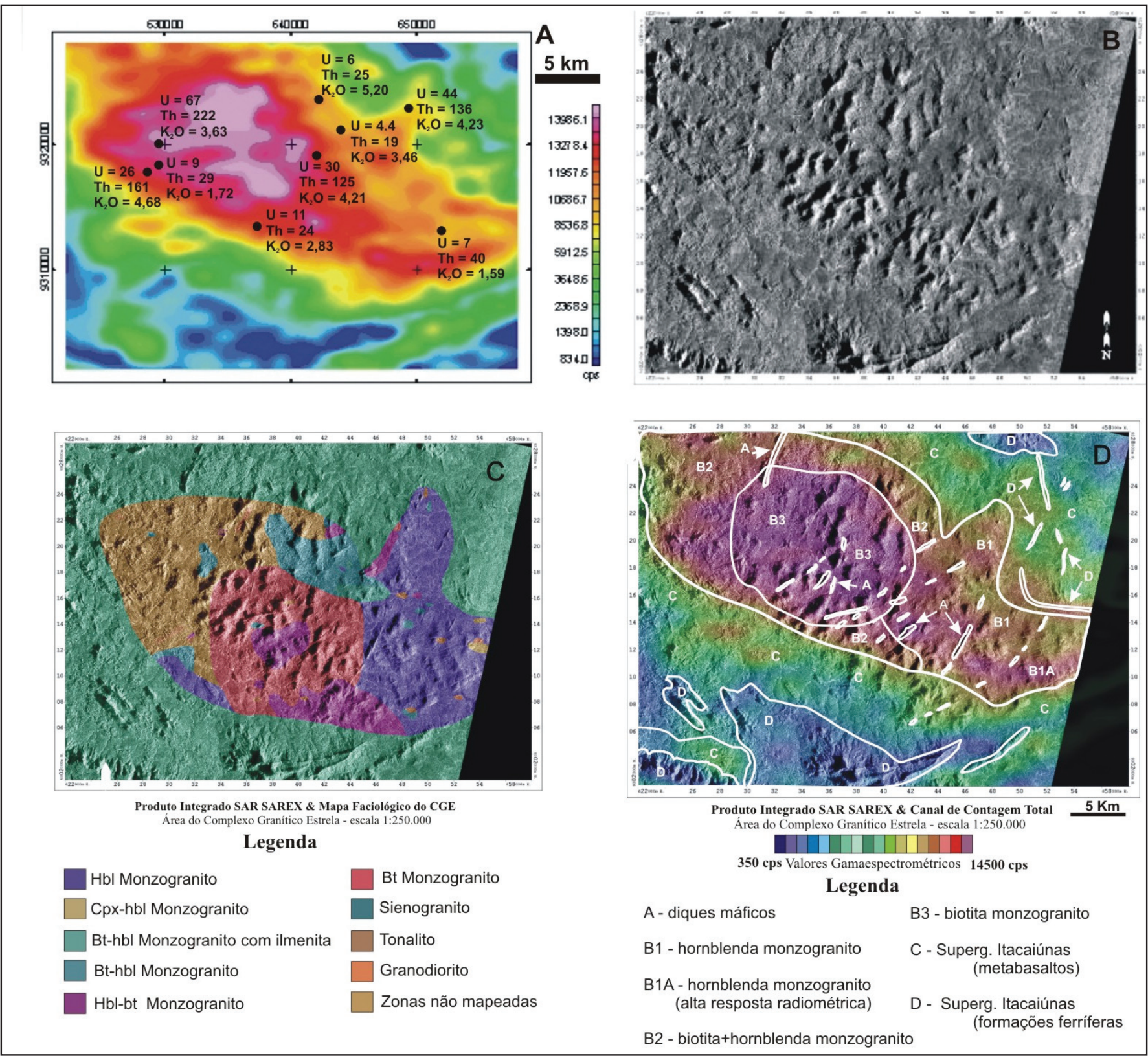

Figura 3. Complexo Granitico Estrela: (A) Imagem Contagem Total (notar locais aproximados de amostras analisadas por Barros (1997) e seus teores de U, Th e $\left.K_{2} O\right)$; (B) Imagem SAR C-HH (SAREX); (C) Produto Integrado SAREX/Fácies Petrográficas de Barros (1997); (D) Produto Integrado SAREX/Contagem Total. 
O corpo do Complexo Granítico Estrela também é marcado por variações significativas na morfologia do seu relevo. Uma alta freqüência de elementos texturais de relevo e de drenagem na parte central do corpo caracteriza um relevo movimentado, contrastando com as áreas mais arrasadas (baixa freqüência de elementos texturais), que ocorrem principalmente no terço NW do corpo. Uma análise mais detalhada das propriedades texturais da imagem permitiu a delimitação de sub-áreas com características homogêneas, indicando variações composicionais/estruturais no complexo. Feições lineares e alinhamentos de drenagem e, com menor expressão superficial, de relevo na direção WNWESE definem a estruturação regional da área e marcam os limites do Complexo Granítico Estrela. Algumas feições lineares de direção ENE-WSW presentes na extremidade leste do granito acompanham a direção da foliação dúctil do granito. Entretanto, o caráter descontínuo destes traços coloca dúvida quanto ao seu significado, se eles marcam a foliação dúctil ou feições rúpteis posteriores.

Aintegração do mapa de fácies petrográficas de Barros (1997) com a imagem SAREX Wide (figura 3C) resume a descrição do parágrafo anterior, ressaltando que as variações composicionais (fácies) no corpo granítico estão associadas, de uma maneira geral, às diferentes respostas de imagem, basicamente às formas de relevo. Finalmente, a figura 3D apresenta a integração digital SAREX Wide/Contagem Total, mostrando a delimitação das principais unidades geológicas da área, baseada na interpretação dos diversos produtos integrados SAR/gama utilizados (Cunha 2003). A avaliação conjunta das respostas radiométricas (variações composicionais) e de radar (geometria superficial) permitiu caracterizar cada unidade geológica em termos de variações de matiz e formas de relevo associadas às diferentes texturas da imagem. Assim, por exemplo, as formações ferríferas são caracterizadas pelas mais baixas respostas radiométricas (azul) e um relevo de cristas retilíneas (D, na figura 3D). No caso de rochas metabásicas e metassedimentares do Supergrupo Itacaiúnas, as respostas radiométricas são moderadas a baixas (verde-amarelado a azul) em um relevo plano (C na figura 3D). As rochas graníticas apresentam as respostas radiométricas mais altas (vermelho a magenta) e um relevo que varia de colinoso a plano (B, na figura 3D). No corpo do Complexo Granítico Estrela (figura 3D) estão delimitadas as principais áreas de ocorrência das diferentes fácies petrográficas (comparar com a figura 3C). Foram separados três domínios distintos dentro do Complexo Granítico Estrela, os quais encontram forte correspondência com as suas variações petrográficas e geoquímicas, facilitando o reconhecimento dos limites entre as fácies. Os teores mais elevados de $\mathrm{K}$, U e Th, observados em biotita monzogranitos, refletem-se nos dados aerogamaespectrométricos, cujas respostas são mais fortes. Isto confirma que a distribuição de fácies é a maior responsável por tais respostas.

A área de ocorrência do biotita monzogranito (B3, na figura 3D) apresenta o relevo mais acidentado (morros arredondados) e as mais altas respostas radiométricas (magenta). As unidades hornblenda monzogranito (B1, na figura 3D) e biotita-hornblenda monzogranito (B2, na figura 3D) apresentam relevos similares, mais rebaixados e planos, diferenciando-se pelas respostas radiométricas um pouco mais altas da unidade $\mathrm{B} 1$ (vermelho a laranja). Os diques máficos (A, na figura 3D) foram identificados, fundamentalmente, pela sua forma de relevo em pequenas serras retilíneas e alinhadas segundo NNE-SSW a NE-SW. Cabe por último salientar que as áreas de ocorrência de menor expressão superficial das fácies mapeadas no Complexo Granítico Estrela por Barros (1997) (figura 3C), em grande parte não puderam ser individualizadas na figura $3 \mathrm{D}$, provavelmente devido ao caráter regional do levantamento aerogamaespectrométrico. Apesar disso, variações sutis de matiz e de relevo observadas no corpo granítico (figura 3D), indicam a necessidade de estudos mais detalhados que possam identificar variações composicionais ainda não mapeadas.

CONCLUSÕES Este estudo vem confirmar a importância da utilização dos produtos integrados digitais e das técnicas de integração digital de dados no mapeamento geológico de áreas pouco conhecidas, de difícil acesso e com espessa cobertura vegetal, como a região da Amazônia Brasileira. A característica intrínseca dos dados SAR de destacar informações da morfologia do terreno, contribuiu sobremaneira na fotointerpretação geológica. Devido a sua boa resolução espacial, estes dados foram extremamente úteis na delimitação dos corpos litológicos, principalmente os de menores dimensões, como diques básicos e algumas cristas de formação ferrífera. Foram fundamentais, também, na identificação das variações de morfologia do relevo no corpo granítico, que permitiram, juntamente com os dados radiométricos, a caracterização de domínios relacionados às diferentes fácies petrográficas.

Os produtos integrados SAR/gama mostraram-se eficientes na discriminação das unidades litológicas da área de estudo, evidenciando alguns aspectos importantes que determinaram a sua aplicabilidade: (1) os dois conjuntos de dados contêm informações que são compatíveis e complementares com relação ao objeto de estudo; (2) uma boa correção geométrica nas imagens foi fundamental para se obter medidas de atributos de mesma localização no terreno; (3) o método de fusão digital IHS buscou integrar o melhor de cada um dos conjuntos de dados, para se obter um produto de valor agregado, com desempenho melhor que os conjuntos analisados individualmente.

Com relação ao Complexo Granítico Estrela, alguns aspectos foram evidenciados no estudo: (1) há uma boa consistência entre os domínios delimitados nos produtos integrados SAR/ Gama e os dados petrográficos e geoquímicos, ou seja, as variações composicionais no corpo do granito determinam variações sutis nas formas de relevo e na intensidade das respostas radiométricas; (2) a capacidade de detecção dessas variações depende, fundamentalmente, do realce da geometria superficial pelos dados SAR (controlado pela resolução espacial e geometria de iluminação) e do nível de detalhe do levantamento aerogamaespectrométrico (controlado pelo espaçamento entre as linhas de vôo e o intervalo entre as medidas); (3) os três grandes domínios identificados nos produtos integrados mostram uma correspondência razoável com as fácies mapeadas, permitindo, em alguns casos, dar mais precisão à localização dos limites entre fácies, através da identificação de quebras de relevo e; (4) o trabalho evidenciou a necessidade da utilização de dados gamaespectrométricos de melhor resolução espacial, que permitissem refinar a interpretação para uma melhor avaliação com os dados petrográficos e geoquímicos existentes.

Agradecimentos A pesquisa foi realizada com as contribuições da Companhia de Pesquisa de Recursos Minerais (Belém), dos doutores Dr. A.C.B. Pires e Dr. M.L.B. Blum do Laboratório de Geofísica Aplicada do Instituto de Geociências (UnB). Os autores W.R. Paradella (300985/90-8) e C.E.M. Barros (300.890/91-5) agradecem ao CNPq pelas respectivas bolsas de Produtividade em Pesquisa. 


\section{Referências}

Araújo O.J.B. \& Maia R.G.N. 1991. Programa Levantamentos Geológicos Básicos do Brasil, Serra dos Carajás. Folha SB.22-Z-A. Estado do Pará. Escala 1: 250.000. Brasília, DNPM/CPRM, 136p.

Barbosa J.P.O. \& Barros C.E.M. 2005. O significado geodinâmico dos granitos cálcio-alcalinos sintectônicos arqueanos da região do Igarapé Gelado, Província Mineral de Carajás. In: SBG, Simp. Nac. Est. Tect., 10, Boletim de Resumos Expandidos, p. 312-314.

Barros C.E.M. 1991. Evolução Petrológica e Estrutural do Gnaisse Estrela, Curionópolis, PA. Dissertação de Mestrado, Centro de Geociências, Universidade Federal do Pará, 134 p.

Barros C.E.M. 1997. Pétrologie et structure du Complexe Granitique Estrela $(2.5 \mathrm{Ga})$ et de son encaissant métavolcano-sédimentaire (Province Métallifère de Carajás, Brésil). Tese de Doutorado, Université Henri Poincaré - Nancy 1, França, 316 p.

Barros C.E.M. \& Barbey P. 1998. A importância da granitogênese tardiarqueana $(2.5 \mathrm{Ga})$ na evolução tectono-metamórfica da Província Mineral de Carajás - o Complexo Granítico Estrela e sua auréola de contato, Revista Brasileira de Geociências, 28(4):513-522.

Barros C.E.M., Barbey P., Boullier A.M. 2001. Role of magma pressure, tectonic stress and crystallization progress in the emplacement of the syntectonic A-type Estrela Granite Complex (Carajás Mineral Province, Brazil), Tectonophysics, 343:93-10.

Barros C.E.M., Barbey P., Costa Jr. P.R. 2002. Venulação e fraturamento hidráulico em rochas metabásicas encaixantes do Complexo Granítico Estrela, Província Mineral de Carajás. In: E. Klein, L.Travassos, M. Vasquez. (Org.). Contribuição à Geologia da Amazônia. 3 ed., SBG, Belém, v. 3, p. 133-142.

Barros C.E.M., Macambira M.J.B., Barbey P., Scheller T. 2004. Dados isotópicos $\mathrm{Pb}-\mathrm{Pb}$ em zircão (evaporação) e $\mathrm{Sm}-\mathrm{Nd}$ do Complexo Granítico Estrela, Província Mineral de Carajás, Brasil: implicações petrológicas e tectônicas. Revista Brasileira de Geociências, 34(4): 531-538.

Bicho C.P. 1994. Processamento digital de imagens aerogeofisicas, Landsat/TM e radar na folha Presidente Médici/RO, com ênfase na caracterização metalogenética da suíte granítica Rio Pardo. Dissertação de Mestrado, Instituto de Geociências, Universidade de Campinas, 103p.

Costa J.B.S., Teixeira N.P., Pinheiro R.V.L., Bermerguy R.L. 1990. Os sistemas estruturais transcorrentes do Cinturão Itacaiúnas na região de Curionópolis, leste do Estado do Pará. In: SBG, Cong. Bras. Geol., 35, Anais, v. 5, p. 2345-2352.

Cunha E.R.S.P. 2003. Integração Digital de Imagens de Radar e Landsat-TM com dados Geológicos e Aerogamaespectrométricos no Auxílio ao Mapeamento Geológico da Região do Complexo Granítico Estrela, Pará. Dissertação de Mestrado, Instituto Nacional de Pesquisas Espaciais, 132 p.

Dias R.R. \& Paradella W.R. 1997. Integração de dados aéreos gamaespectrométricos com imagens TM-Landsat no mapeamento geológico da área do Pojuca, província mineral de Carajás. Revista Brasileira de Geofisica, 15(1):23-33.

DOCEGEO (Rio Doce Geologia e Mineração), 1988. Revisão litoestratigráfica da Província Mineral de Carajás. In: SBG, Cong. Bras. Geol., 35. Província Mineral de Carajás Litoestratigrafia e principais depósitos minerais, Anexo aos Anais, p. 11-59.

Gapais D, 1989. Shear structures within deformed granites: Mechanical and thermal indicators. Geology, 17: 1144-1147.

Geosoft 2000. Geosoft Oasis Montaj (versão. 5.1), Geosoft Inc., Toronto, Canadá

Gomes A.K.B. \& Dall'Agnol R. 2003. Geoquímica dos Granitóides da Região a Leste de Canaã dos Carajás. In: SBGq, 9, Cong. Bras. Geoq, Boletim de Resumos Expandidos, p.781-783.

Harris J., Bowie C., Rencz A.N., Graham D. 1994. Computer-enhancement technique for the integration of remotely sensed, geophysical and thematic data for the Geoscience. Canadian Journal of Remote Sensing, 20(3):210-221.

Harris J. R., Viljoen D. W., Rencz A. N. 1999. Integration and Visualization of Geoscience Data. In: A. N. Rencz (Ed) Remote Sensing for the Earth Sciences. J. Wiley \& Sons, Am. Soc. Photog. \& R.S. Vol. 3, p. 307-354.
Huhn S.B., Macambira M.J.B. \& Dall'Agnol R. 1999. Geologia e Geocronologia $\mathrm{Pb} / \mathrm{Pb}$ do Granito Alcalino Arqueano Planalto, Região da Serra do Rabo, Carajás, PA. In: SBG, Simp. Geol. Amaz., 6, Manaus, Anais, 1:463-466.

Lima F. D. \& Pinheiro R.V.L. 2001.Formação Gorotire: Considerações sobre uma unidade siliciclástica particular da Serra dos Carajás - PA. In: N.J. Reis \& M.A.S. Monteiro. (Org.) Contribuições à Geologia da Amazônia, SBG, Manaus, v. 2, p. 201-224.

Macambira E.M.B., Jorge-João X.S., Souza E.C. 1996. Geologic and petrological aspects of the Plaquê Granite - Southeastern of Pará State. In: SBG, Symposim Archean Terranes of the South American Platform, Extended abstracts, p. 73-75.

Machado N., Lindenmayer Z., Krogh T.H., Lindenmayer D. 1991. $\mathrm{U}-\mathrm{Pb}$ geochronology of Archean magmatism and basement reactivation in the Carajás area, Amazon shield, Brazil. Precambrian Research, 49: 329-354

Mather P. M. 1999. Computer Processing of Remotely-Sensed Images: An Introduction. 2 ed., Ed. J. Wiley \& Sons, New York, 292 p.

Minty B.R.S. 1997. Fundamentals of airborne gamma-ray spectrometry. Journal of Australian Geogical and Geophysics, 17(2):39-50.

Paradella W.R., Bignelli P.A., Veneziani P., Piestch R.W., Toutin T. 1997. Airborne and spaceborne synthetic aperture radar (SAR) integration with Landsat TM and gamma ray spectrometry for geological mapping in a tropical rain forest environment, the Carajás Mineral Province, Brazil. International Journal of Remote Sensing, 18(7):1483-1501.

Paradella W.R., Santos A.R., Dall'Agnol R., Pietsch R.W., Sant'Anna M.V. 1998. A geological investigation based on airborne (SAREX) and spaceborne (RADARSAT-1) SAR integrated products in the central Serra dos Carajás granite area Brazil. Canadian Journal of Remote Sensing, 21(4):376-392.

PCI 2001. Geomatica, (OESE, Xpace Reference Manuals: version 8.2), PCI Geomatics Inc., Richmond Hill, Canadá

Pedroso E. Rivard B., Crósta A. P., Souza Filho C. R., Miranda F. P. 2001. Reconnaissance geologic mapping in the Tapajós Mineral Province, Brazilian Amazon, using spaceborne SAR imagery and airborne geophysics. Canadian Journal of Remote Sensing, 27(6):669-678.

Pidgeon R.T., Macambira M.J.B., Lafon J.M. 2000.Th-U-Pb isotopic systems and internal structures of complex zircons from an enderbite from the Pium Complex, Carajás Province, Brazil: evidence for the ages of granulites facies metamorphism and the protolith of the enderbite. Chem. Geol., 166:159-171.

Pinheiro R.V.L. \& Holdsworth R.E. 1997.Reactivation of Archean strike-slip fault systems, Amazon region, Brazil. J. Geol. Soc. London, 154:99-103.

Rivalenti G., Mazzucchelli M., Girardi V.A.V., Cavazzini G., Finatti C., Barbieri M.A., Teixeira W. 1998. Petrogenesis of the paleoproterozoic basalt-andesite-rhyolite dyke association in the Carajas region, Amazonian craton. Lithos, 43:235-265.

Rolim S.B.A. 1993. Avaliação do uso da transformação IHS na integração de dados geofisicos (aeromagnetometria) e de sensoriamento remoto (TM Landsat) para a investigação geológica na área do Pojuca (Serra dos Carajás, PA). Dissertação de Mestrado, Instituto Nacional de Pesquisas Espaciais, 133p.

Santos A.R., Paradella W.R., Veneziani P., Liu C.C., Sant'Anna M.V. 1997. Integração de dados SAR-TM e SAR-GAMA em estudos geológicos na Província Mineral de Carajás (Brasil). In: Simposio Latinoamericano de Percepcion Remota, 8, Mérida, Venezuela,Geo 005, Atas, CD-ROM.

Santos S.L.C. 1999. Integração digital de dados Radarsat S2, TMLandsat e Aerogamaespectrométricos: contribuição ao estudo de corpos graníticos mineralizados da Província Estanifera de Rondônia. Dissertação de Mestrado, Instituto Nacional de Pesquisas Espaciais, $168 \mathrm{p}$

Sardinha A.S., Barros C.E.M., Krymsky R. 2006. Geology, geochemistry and U-Pb geochronology of the Archean (2.74 Ga) Serra do Rabo granite stocks, Carajás Metallogenetic Province, northern Brazil. Journal of South American Earth Sciences, 20:327-339. 
Siqueira A.J.B. 2003. Avaliação de radares imageadores aerotransportados e orbitais no mapeamento litoestrutural na Província Mineral de Carajás, área do prospecto Águas Claras. Tese de doutoramento. Instituto Nacional de Pesquisas Espaciais, 273p.

Soares A.V., Santos A.B., Vieira E.A., Bella V.M., Martins L.P.B. 1994. Área Águas Claras: contexto geológico e mineralizações. In: Simp. Geol. Amaz., 4, Boletim de Resumos Expandidos, p. 379-382.

Streckeisen A.L. 1976. To each plutonic rock its proper name. EarthScience Reviews, 12:1-33.

Teruyia R. K. 2002. Integração Digital de Dados Multifontes no Estudo Geológico do Granito Cigano, Província Mineral de Carajás, $P A$. Dissertação de Mestrado, Instituto Nacional de Pesquisas Espaciais, $137 \mathrm{p}$.

Vasconcellos R.M., Metelo M.J., Motta A.C., Gomes R.D. 1994. Ge- ofisica em levantamentos geológicos no Brasil. CPRM, Rio de Janeiro, $165 \mathrm{p}$

Veneziani P. \& Anjos C.E. 1982. Metodologia de interpretação de dados de sensoriamento remoto e aplicações em geologia. São José dos Campos, INPE, 1982. 61p. (INPE-2227-MD/014).

Veneziani P., Santos A.R., Paradella W.R. 2004. A evolução tectono-estratigráfica da Província Mineral de Carajás: um modelo com base em dados de sensores remotos orbitais (SAR-C RADARSAT-1,TM LANDSAT-5), aerogeofísico e dados de campo. Revista Brasileira de Geociências, 34(1):67-78.

Manuscrito A-1658

Revisão aceita em 3 de agosto de 2006 